\title{
Modernity and Technology—An Afterword
}

Arie Rip

Modernity and technology are too important to study in isolation, as Tom Misa indicates in a proposition in his chapter. This implies a further proposition about technology and modernity being interconnected. It is this idea of interconnectedness that led us to deplore the "great divide" between detailed technology studies, with their claim of situated developments and contingency, and abstract or theoretical discussions of modernity. We exaggerated a bit in order to make a point and set up a twin argument for an empirical turn in modernity studies and for recognizing broader structures and long-term dynamics in technology studies. Conjuring up a field of technology and modernity studies in this way was made easier because the authors had already been looking for bridges across this great divide before, and they could build on the work of colleagues and discussions with them at the November 1999 workshop at the University of Twente. In other words, we did not start from zero. Yet the divide between technology studies and modernity studies remains difficult to bridge. There are methodological challenges, often summarized as the contrast between micro (or local) and macro (or global) levels of analysis. There are also substantial issues about the nature of modernity (and of technology, for that matter) and about the different perspectives that can be brought to bear, especially when further diagnosis is required that concerns openings for change and desirable directions.

Tom Misa's introduction outlined a program but also left room for the other authors to analyze the tensions and offer their own approaches and insights. It is fitting to look back, at the end of this volume, and ask how far we have come. In this way we continue the conversation about 
modernity and technology among the authors, and now also include the readers of this volume.

The conversation is about methods and approaches (of modernity studies and technology studies, and their rapprochement) and about substance, namely, concerns about our world with its modernist projections, its technological achievements, and its vulnerabilities. Thus, while the conversation begins with the conviction that academic reflection can contribute to real-world issues, it is not "just" an academic discussion. The chapters in this volume amply testify to real-world issues when they discuss infrastructures, surveillance, the environment and the chemical industry, and national innovation systems. There is also a concern with the dominance of modernist regimes and what, rightly or wrongly, they exclude; and thus with the possibility of lateral views, or ruptures, as these occur or are sought after. In this way, reflections may create openings for transformation.

Going on from there, one might try to identify concrete possibilities for change and to justify such attempts. There is a risk of reification because such justifications must be a platform for action. Recognizing their constructed character is necessary but may run another risk when contingency is emphasized and agency becomes irrelevant. The idea of co-construction emphasized in this book transcends contingency, but does not lead to simple suggestions for individual agency. The ambivalence can be addressed by what Barbara Marshall in her chapter calls "strategic essentialism"; she refers specifically to feminist theory and feminist practice, but the approach is general.

In this afterword I touch on these issues. My interest is not only in showing what we have learned, but also in identifying what remains to be taken up. I start with the methodological issue of how one can "see" co-construction at work, or the global in the local.

\section{Methodological Issues}

The chapters of this book offer windows on the modern world and its technologies. Through such windows we "see" something. Think of how anecdotes and examples draw our attention when they let us recognize something that strikes us as important and relevant. This is how 
Misa presents examples of modern and postmodern technologies. More than just slick corporate packaging is at play in the contrast between the IBM Museum, an exhibition on computers in the modern world by IBM, and Sony World, a similar exhibition by Sony. Both were staged in New York; IBM's exhibition exemplified the hierarchical and functional mode, Sony's the fluid and imagery mode. The contrast signaled modern versus postmodern (whatever that may be), with overtones of America being prisoner of its earlier successes and Japan moving quicker and more playfully (at least in consumer products). The contrast between the two exhibitions-and their link with corporate culture and corporate images-functions as a window on the modern world and carries a certain immediacy. Don Slater, in his chapter, adds the idea of a "crystallizing example" that clinches earlier groping toward understanding.

How can such examples and their attendant analysis be windows? The local and specific practices allow us a view on what is of wider significance. Our view is of the global as it appears in the local and is refracted by it (in turn, the global structures the local). Windows on the world (as offered by analysts) reveal our intimations about the world. Something we knew, perhaps, but could not articulate. An example gives us a sense of recognition and helps us (analysts, readers) to articulate our intimations. Obviously, there are risks to the analyst: what are the grounds for recognizing one structure or trend rather than another? There are ways to handle this problem, such as triangulation or reflective equilibrium. What remains is the immediateness of the example and how it is structured. This derives from the story it tells. In a story, the global can be incorporated and made explicit by zooming in on a word or a phrase-say, Japan versus America.

In Junichi Murata's chapter, we hear about domestic industrial expositions in Japan in the Meiji era, the fifth such exposition in 1903 drawing more than four million visitors to Osaka. With such popular interest in modern technologies, it becomes understandable that the introduction of trains pulled by steam locomotives was a running showcase: people could see the modern western world "through" a train. These windows on modernity were, of course, vastly popular in the West itself. Johan Schot reminds us of the deliberate technological framing of modernity at the 1939 New York World's Fair. And for that matter, for 
years Amsterdam's Schiphol Airport had greater revenues from (nonflying) visitors paying for a glimpse of modernity than from airplanes actually flying.

This notion of a "window" is similar to Dorothy Smith's argument about the situated nature of knowledge and how it can be unfolded to show the "apparatus" involved in the background-even in the everydaylife case of walking your dog in the neighborhood (Smith 1987, 1990). Phrased in this way, it is a purely methodological point about local and global. There is also a substantive aspect, however. If we use the right windows, we can "see" something interesting and important about technology and modernity that we had not seen before. Schot takes this approach, highlighting slices of development over time, with recent changes in modern technology and modern politics becoming salient. In addition, the "global" is not just a methodological category, but also a force for better or for worse, as is very clear in the chapters by David Hess, Arthur Mol, and Haider Khan.

Such windows also work by surprising us. We see things we had not imagined, but now that we are told about them, our vision is expanded. Don Slater shows how Trinidadians in their use of the Internet take up modernity enthusiastically, as a way to reinforce and expand an identity from the periphery. In a study of telecommunication technology and modernity in Indonesia, we identified a dual dynamic: a strong push from the state to create a national identity in the Indonesian archipelago, through information and communication technologies, and a heterogeneous, bottom-up dynamic of creating Internet access and exchange driven by engineers and other users, and now including Indonesian-style Internet cafes. It is interesting that the metaphor of guerilla tactics was used, which in Indonesia has nationalistic overtones (independence having been fought for and achieved through such tactics). Yet now such high-tech guerilla tactics have helped to undermine President Suharto's New Order and its reference to high-tech modernization (Barker et al. 2001). Through such an analysis, we can see-in action, as it were-the co-construction of modernity and technology.

Closer by, literally just outside our homes, we can find surprises as well. What about the morality of sidewalks? They are part of a functional separation between the different modes of using a street as a public 
space. This became important in the early twentieth century with the multiplication of vehicles using the street (bicycles and motor cars, carts and horse-drawn carriages, as well as various trams). Allocating parts of the street to different kinds of users disciplined each category of users (socioculturally and materially) and created a way to optimize streets and their use. Over the decades of the twentieth century, this disciplining led at first to encouraging motor car traffic — an icon of modernityand more recently, to attempts to limit motor cars' freedom. The infrastructure of city streets (another example for the analysis in Paul Edwards' chapter) was actively co-constructed by engineers and city planners, on the drawing boards and in response to actual patterns of use. Cross-profiles of city streets (presenting the multidimensionality of electricity cables, telephone wires, sewers, gas lines) in relation to their various users became a planning and construction tool to master this multidimensional complexity (Disco et al. 2002). Technological complexity increased, but there is a continuity with the earlier hygienic movement and modernist city planning-think of the Italian Futurists' multilevel transport systems in their city planning schemes before World War I. In contrast to utopian schemes, problems needed to be solved on location, and the messiness had to be confronted time and again. Cities were shot through with complexity-postmodern?-before they were rationalized, and their modernist reconstruction cannot completely contain their basic heterogeneity.

In the infrastructure of cities, then, we "see" how ideals and structures of modernity interact with local practices and evolving technologies. The tangle that results gets tied up with material "knots" of cross-profiles and their planning, with institutionalized disciplining of behavior and interaction, and with the professionals who claim expertise over the construction and reconstruction of cities. Clearly, coconstruction can be traced; it can work as a methodological point of departure. As Philip Brey argues in his chapter, and the chapters in parts II and III show by example, there is interaction between different levels and scales. In particular, there is the historical phenomenon of the emergence of institutions and institutionalized activities between the local and the global, between the micro and the macro, that mediate the interactions. Anthony Giddens' mechanisms-money, timetables, and expert 
systems-that disembed social life depend on such mediation for their effectiveness. Thus Misa's (1994) argument for a middle-level methodology becomes even more pressing. There is an emerging and by now wellarticulated intermediate layer in modern societies that carries the work of co-construction. Its study must be one of the preferred "windows."

There is a final methodological point to be made: looking out of a window, one positions oneself as an observer. The framing involved in using a window to look at the world is not my main concern here, even if framing is an important phenomenon in social life. Framing a problem in a certain way (modernist or otherwise) and being able to get that frame accepted allows certain solutions to be more successful than others. The struggles analyzed in the chapters of part III show many examples.

What I want to comment on is how the question of agency has been forced to the background by the concern to show the co-construction of modernity and technology. Thus the modernist view of agency as purposeful action leading to the achievement (or not) of an intended goal was not thematized and compared with other views in which agency is more broadly seen as making a difference (see Law 1994). Andrew Feenberg's observation in his chapter is particularly illuminating: "Human beings and their technologies are involved in a co-construction without origin." Agency can then be no more than modulation of such processes informed by an understanding of their dynamics. However, knowing how such tangles get tied up, and how mediators become established, one might want to anticipate how and where to act. Some "knots," and some mediating institutions, are better places than others. Arriving at them is a sort of bootstrap operation. We can then ask what productive bootstrap operations might look like, and whether there might be productive arrangements generally. In the end, this would lead to an interest in the "constitution" of a late-modern technological society, and attempts to improve it.

Haider Khan in his chapter actually proposes a new arrangement, a POLIS, as part of such a constitution. Because his is an explicit attempt at constitution building, as it were, it can in principle be evaluated for its possibilities and limitations. A POLIS should overcome limitations of national innovation systems by introducing feedback loops and more bottom-up learning - a bootstrap operation. It is not yet integrated with 
the references in his chapter to differentials in power structures and to making a difference, and this highlights a challenge to the co-construction approach. Co-construction suggests activities that lead to outcomes, but it is not quite clear whose activities and which outcomes. The critical tradition would introduce the reference to power structures; Langdon Winner's criticism of recent technology studies is a clear example (see Winner 2001). In addition to the obvious reply that power structures are constructed as well, I would argue that it is important to understand the limitations of modernist views of agency and the fact that critical action can easily fall into the trap of alternative modernism. In our work on "constructive technology assessment" (see Rip et al. 1995; Schot, chapter 9, this volume) we had to address this issue. We have come up with notions such as modulating processes (of the co-evolution of technology and society), based on an understanding of how prospective structures are projected as promising options and, to some extent, made true (Kemp et al. 2001; van Lente and Rip 1998).

\section{A Late-Modern Technological World}

Windows on the world give us partial views, but these will add up to an amalgam, as David Hess calls it in his chapter, or a kaleidoscopic closure, an intriguing phrase coined by Murray (1997) when she analyzed interacting narratives made possible through the Internet. What kind of world becomes visible in this way? And what sort of history of technology and modernity can be articulated?

Paul Edwards, in the opening paragraphs of his chapter, suggests a history of successive backgrounding and naturalization of technologies as invisible infrastructures that are assumed to function smoothly and serve their purpose. A lot of ingenuity and care is invested in not disappointing this assumption. Engineers in particular feel this ethics of care for the world of artifacts. It is part of their mandate, as it were, with another part deriving from their working toward technological progress, and being allowed to do so relatively autonomously.

The engineers' thoroughgoing modernism- “we can do great things, if you let us"-is very visible in the late nineteenth and early twentieth centuries. It is the same period in which many social groups called for 
emancipation and anarchists played havoc with the existing order. Electricity started to transform the sociotechnical landscape. Airplanes captured the imagination, with dreams of aviation elevating humankind-it was even called "the winged gospel” (Corn 1983). Investments in civil aviation continued even if they did not turn a profit until after World War II. By now, aviation has become part of the infrastructure of modern society. Its technical nature and functioning have become invisible for the general public and politicians. With the naturalization of the air travel infrastructure came an inevitable lack of attention to its vulnerabilities-with the attendant surprise on September 11, 2001, that terrorists could turn this modern infrastructure against its own projections of security.

There are other storylines about the co-construction of modernity and technology, but all of them appear to have an ironic twist of earlier successes creating problems. Is this a defining characteristic of the coconstruction of technology and modernity in the late twentieth century? Think of plastics and other new materials being hailed as the key to the future and later condemned as unsafe and a threat to the environment. Or of surveillance, an age-old technology materializing in panoptic arrangements and then partially dematerializing again through information and communication technologies-even while cameras and other physical devices and hybrid items like barcodes remain of central importance. David Lyon in his chapter suggests that technological dependence coupled with consumerism (both features of modernity) are together changing modernity out of recognition, with surveillance of various kinds getting a central position in this new or postmodernity.

In health care, the co-construction with modernity is particular striking, with the hygienist and eugenic movements of the nineteenth and early twentieth century, the strong development of sanitation and better housing, new medical drugs and therapies, and the experience of the national-socialistic Third Reich-in its own way strongly modernist. After World War II, eugenics was transformed into genetic counseling, with a strong individualistic thrust. Individual autonomy in health care, especially in clinical genetics, is now a sacred principle-while tensions appear because of advances in genetics and the wider introduction of preventive medicine. 
Just as we see technologies in the plural, there might be modernities in the plural. Why do we speak of technology and of modernity as being of one kind? The chapters in this book show their variety, and many of the authors insist on the limitations of abstract notions of technology (or for that matter, of modernity). Still, the abstract notion of technology is widely available as one of the modernist keywords that emerged as forceful in the course of the nineteenth century-hence, a Massachusetts Institute of Technology. What is needed is an analysis of how and why such abstract notions emerge and can be forceful, not just with modernity theorists, but also with various actors.

To indicate the abstract, iconic character of technology in a text, one can write it in capitals: TECHNOLOGY. Indeed, the transformation of technology as the term was used in the early nineteenth century into the iconic TECHNOLOGY of the twentieth century can be traced historically; this is a research project that is long overdue. Actors rarely use the term "modernity," but they often appeal to the "modern" and "being modern." And this has inclusion and exclusion effects (just as declaring a "modern period" in history includes "us" and excludes "them," as Tom Misa phrases it). Views of technological progress and its modernizing role imply collusion between TECHNOLOGY and MODERNITY. This continues to the present, even if we are sadder and wiser.

In Don Slater's chapter, the rhetorical connections between INTERNET and MODERNITY are particularly striking; David Lyon sees SURVEILLANCE as a continuation of MODERNITY; while David Hess shows how alternative therapies become accepted as "complementary" to modern medicine. (SUSTAINABILITY is yet another such icon.)

In these alliances and sometimes battles of abstract notionsideographs, as van Lente (1993) calls them-one sees the creation of protected spaces for further development (as with technological progress in most of the twentieth century) as well as the creation of specific modernities linked to the particular combination that is dominant. And as happened with TECHNOLOGY and MODERNITY in the late twentieth century, when one is criticized, they both suffer. This can be a stimulus for change, as in the case of ecological modernization in the chemical industry, which Arthur Mol in his chapter offers as an argument in the analysts' discussions of MODERNITY. 
Under these iconic and thus forceful terms, a variety of developments occur that are shaped by the icons. What is more, the constellation of icons shifts because of such processes and their outcomes. As it turns out, the chapters take a particular cross section through this multilevel and kaleidoscopic co-construction process. They tend to discuss technologies as they appear, more or less ready-made, in our societies. Tom Misa's phrase about the "infrastructure of daily life, choreographing the members of modern societies" characterizes this tendency beautifully, and Paul Edwards adds to this when he emphasizes "fluency" in infrastructures.

Yet, on balance, the chapters in this volume say too little about the contextual dynamics of new technologies and their embedding in society. Our conversation on technology and modernity needs to be widened to include evolutionary economics and recent innovation studies (see Rip and Kemp 1998), which are mentioned only in passing. There is reference to innovation systems, as when Haidar Khan discusses Taiwan. Johan Schot, in his final proposal addresses the dynamics of development, but remains programmatic. Arthur Mol assumes that there are such dynamics (in the chemical industry).

My reason for highlighting this limitation to our book is that we may well be experiencing a new wave of engineers' (and politicians') technological modernism. This can be seen in the push for biotechnology, in spite of its being contested; the massive R\&D investment in the life sciences; and not least the promises made for genomics whether "green" (agricultural) or "red" (medical). True, these are heavily hyped visions, but they capture the imagination. Why is it that they capture our imagination in the late-modern world? I see a new version of technological modernism, linked to the search for, and promise of, upstream solutions for downstream problems. It is a further variant on the modernist idea of action as emanating from a source, and leading to effects because of the nature of this source, rather than through processes of coconstruction.

In genomics, this view is particularly clear. It was pushed strongly because of its scientific promise, and taken up by policy makers to show that they could support important research. Heads of state in the United States and the United Kingdom wanted to announce the unraveling of 
the human genome. Collusion of scientists and policy makers in priority programs, each for their own reasons, is not unusual. But here there is a specific dream: if you know the genetic map and how it relates to functions and dysfunctions, you can purposefully manipulate a gene and successfully prevent an illness. This is the age-old modernist dream: causal links from an agent source to desired effects. Moreover, genomics is linked to another modernist feature, individualization, with the promise of gene passports allowing individualized therapy. Symbolic aspects are not far behind: "The genome is viewed as the core of our nature, determining both our individuality and our species identity. [It is] the true essence of human nature, with external influences considered as accidental events" (Mauron 2001: p. 831).

Ironically, the Human Genome Project itself has produced a setback to this modernist program: there are far fewer human genes than expected (about one-third of the original estimates). This implies that genes are polyvalent; not so much their mere existence but rather the regulation of their expression becomes important. Some genomics researchers want to keep up the front of the original promises. But for human diagnosis and therapy, and for producing better plant (and perhaps animal) varieties, the message is clear: there will be no linear relationship between genetic information, intervention, and impact.

A new wave of technological modernism is surely building in nanotechnology, which is projected as transforming the economy of the twenty-first century. Nanotechnology is defined in part by its scale, but also by the ability to manipulate matter on the nano scale and to produce materials and devices with properties that will "make a difference" at the phenomenal level. There is debate about how far we can go in this direction (Smalley 2001; Drexler 2001), but the direction itself is clear: by manipulating the minute and by creating devices, we can set in motion a chain of effects that will make a difference "downstream." There are indeed promising devices, but so far the successful ones, such as sensors and a "lab-on-a-chip," are devices for analysis, not for creating a difference.

There is a storyline of (modernist) promise and (subsequent) disappointment here. The actual co-construction processes will determine the specific outcomes and thus the new technological modernity. That is 
why it is important to understand the contextual dynamics of the development of new technologies and their actual embedding in society.

\section{New Modernities}

There are new technologies, but also new modernities. Simplifying a more complex process, one might argue that in the West the environmental movement introduced pluralism with respect to the alliance between technology and modernity. Multiculturalism is becoming a further challenge in the West, and globally as well, in a postcolonial world where American dominance is not only criticized but can also be undermined, at least for a time, as September 11th has shown. Adopting the U.S. State Department's view for just a moment, very modern means (flying modernist jets into modernist skyscrapers) were used to further antimodern ends (ridding the East of the West). There are multiple oversimplifications here, in particular the equation of "the" West with "the" modern (Harootunian 2000a,b), but the point is that there are cracks in the modernist alliance with technology.

North-South differences introduce a further tension. Within the South itself, this tension is played out between technoeconomic ambitions that almost of necessity reflect western-modernist approaches, and postcolonial resistance to such western dominance. In a country like South Africa, both tendencies are visible in the ruling African National Congress. Mutual “othering” occurs, with Said's (1995) diagnosis of orientalism in the West being counterposed by an African Renaissance movement following the same pattern.

For new technology, "othering" appears to occur equally in the West, North, South, and East. It appears in different forms, but all in response to the danger of an existing order being broken by the novel entrant. Modernity supports novelty, but on its own terms, and will push aside the novelties and variety that do not conform to these terms. In this sense, Arthur Mol's intriguing phrase "the modernization of modernity" (pace Beck) may not be able to accommodate plurality and multiculturalism.

Co-construction is a broader concept, but its recognition of multiple agency is not enough to create concerted effort in desirable directions. As David Hess would put it, a multiplicity of modernities also drains 
modernity of its emancipatory potential, undermining the grounds for normative critique. On the other hand, as Don Slater emphasizes, modernity is under construction (always, but definitely now), and emancipation might be a contingent effect.

Does co-construction, then, lead us to an impasse? Perhaps, but let us go back to the actors, using a "window on the world." The first window is about the Royal Dutch-Shell Company building scenarios of a future world. One of their methodological prescriptions is to identify key developments that can be assumed to be present in all scenarios, and then introduce variety. Such key developments are called TINAs (there is no alternative). In the Shell scenarios, TINA is about information and communication technologies and their effects. Is this a projection of technological determinism? Or a realistic diagnosis of how the co-evolution of technology and society turns out to work in our world?

Such scenarios are "theories in practice," and make a normative point by accepting a particular development as TINA. This becomes clear when one uses a window on another part of the modern world, where agricultural science (and to a lesser extent medical science) has to come to terms with local specificities and individual particularities. The modernist approach is to position the local and individual as specifications of global regularities and laws. Knowing the composition of the soil, or the gene makeup of the individual, one can prescribe what is necessary. This modernist approach runs into difficulties. In agriculture, the history of the (living) soil, and thus local knowledge, turns out to be important. In the medical sector, one sees a proliferation of alternative and complementary medicine, as David Hess outlines.

There need not be a contrast with the irresistible development and use of information and communication technologies. Agriculture and medicine can and do profit from the new possibilities. The tension that remains is between the disciplining requirements of information and communication technologies (a code is necessary to transmit) and the local idiosyncracies. In other words, there are elements of governance embedded in the various technologies, which in practice add up to hybrid and possibly conflicting governance.

The question of governance might lead to a fifth proposal, which would complete Tom Misa's introductory chapter. One element must be 
about the importance of spaces rather than action. Spaces offer opportunities for agency and for a variety of agents (depending on the nature of the space). Zygmunt Bauman has an intriguing phrase about living in the cracks of modernity (see Law 1994). Such cracks should become spaces; and agency in those spaces might shift the modernist structures a bit.

A second element starts with the recognition that co-construction happens anyway and adds that actors will anticipate and reflect and act strategically all the time. In and through their interactions, there is an emergent design effort in the small and in the large. Such design efforts should not be modernist, starting with a concept or prototype that must then be implemented. As designers, in particular in information and communication technology, but also in other technologies and projects, have been learning-often the hard way-interactive design that includes input from projected users is very important.

These two elements do not add up to a fifth proposal that can be formulated in one sentence. But such a proposal must be about creating space and making sure that something productive is done in that space. One cannot and should not define beforehand what is to "count" as productive. Descriptively, one could say that modernities and technologies co-evolve, interacting on the basis of relative autonomy. The key question is what this co-evolution will lead to and whether one can use an understanding of the dynamics and patterns as products of co-evolution to shape one's own and perhaps others' actions oriented toward an unknown future.

The fifth proposal might be the affirmative version of this question: it is possible to find patterns in co-evolution and show that they will return. But since these patterns are co-constructed, the actors involved must be addressed and mobilized to improve anticipation, reflection, and learning. 